\title{
ĐÁNH GIÁ KẾT QUẢ PHÃU THUẬT KÉN PHẾ QUẢN TẠI BỆNH VIỆN PHỔI TRUNG ƯONG GIAI ĐOẠN 2011- 2015
}

\author{
Khiếu Mạnh Cuờng*, Đinh Văn Lượng*, Nguyễn Lê Vinh* \\ Ngô Thị Thúy Quỳnh*, Đoàn Quốc Hung**
}

TÓM TẮT: Kén phế quản là một dị tật bẩm sinh của phổi cần chẩn đoán và phẫu thuật sớm. 44 trương hợp (19 nam, 25 nũ) sau phẫu thuật có kết quả mô bệnh học là kén phế quản, độ tuổi trung bình 41,8 tuổi. Triệu chứng chủ yếu ho, ho máu, đau ngục, khó thở, sốt. Hình ảnh trên XQ ngực thuoòng quy và $C T$ Scanner ngự dạng tổn thương chủ yếu: kén khí, kén có mức dịch khí, khối mờ đều, khối mò̀ trong kén khí. Kén phế quản trong phổi tổn thuoong bên phải chiếm uu thế, trong khi đó kén phế quản trung thất phát triển bên trái chiếm uu thế. Điều trị chủ yếu là phẫu thuật, với kén phế quản trung thất cắt kén, kén phế quản trong phổi chủ yếu cắt thùy phổi. Biến chứng trong, sóm ngày đầu sau mổ it, trong khi đó biến chứng sau mổ muộn hơn nhẹ và xủ lý đơn giản chủ yếu ổ dịch khi khu trú. Thời gian nằm viện sau mổ trung bình 16,39 ngày. $100 \%$ bệnh nhân ổn định ra viện với hình ảnh XQ trong 41 trường hợp phổi nở sát thành ngục, 3 trường hơp có dày dính màng phổi.

SUMMARY: Bronchogenic cysts, which is a congentinal pulmonary malformation needs to be diagnosed and treaded early. 44 cases were treated at our hospital were confirmed with histologic examination. There was 19 males and 25 females. Mean age was 41,86. Symptoms comment were cough, fever, pain and dyspnea, hemoptysis. Images in Xray and CT-scanner were emphycematous, Hemogenous shadow, air-fluid level, Hemogenous shadow in cyst. Pulmonary bronchogenic cyst was predominant in the right side, other wise mediastinal bronchogenic cyst was seen more frequent in the left side. . Surgical procedure was done treatment bronchogenic cysts: lobectomy with bronchogenic cyst and Surgical excision with the cyst mediastinal was approached. Postoperatve complications are comment air or fluid in plueral cavity. The mean postoperative hospital stay 16,39 days.

\section{I. ĐẶT VẤN ĐỀ}

Sự phát triển bất thường của mầm phổi trong thời kỳ bào thai xảy ra từ tuần thứ 4 đến tuần thứ 6 của thai kỳ tạo nên một số dị tật bẩm sinh của phế quản và phổi như: Kén phế quản, dị dạng nang tuyến bẩm sinh, khí phế thũng, phổi biệt lập...Kén phế quản là một trong những dị tật bảm sinh hiếm gặp của phổi, có thể được chẩn đoán trước sinh, ở trẻ sơ sinh hoặc trẻ nhỏ bởi vì các triệu chứng chèn ép cơ quan lân cận. Ở người lớn thường được chẩn đoán khi chụp phim $\mathrm{X}$ Quang phổi kiểm tra sức khỏe hoặc có biến chứng: Viêm nhiễm, đau ngực, khó thở, vỡ kén, ho máu.....

Triệu chứng lâm sàng của kén phế quản không đặc hiệu, chẩn đoán kén phế quản chủ yếu dựa vào hình ảnh: XQ phổi thường quy, CLVT. Điều trị triệt để duy nhất bằng phẫu thuật: cắt bỏ kén hoặc cắt thùy phổi hay phần thùy phổi chứa kén phế quản.

Chúng tôi tổng kết các trường hợp kén phế quản được phẫu thuật tại bệnh viện Phổi trung ương giai đoạn 2011- 2015 nhằm nhận xét đặc điểm bệnh lý và kết quả sớm sau phẫu thuật điều trị dị tật này. \section{CÚU}

II. ĐỐI TƯợNG VÀ PHƯƠNG PHÁP NGHIÊN

\section{1. Đối tượng nghiên cứu}

2.1.1. Đối tựng nghiên cứu: Các bệnh nhân sau điều trị phẫu thuật có kết quả mô bệnh là kén phế quản tại Bệnh viện Phổi Trung ương.

\subsubsection{Tiêu chuẩn chọn bệnh nhân}

- Có chẩn đoán giải phẫu bệnh là kén phế quản.

- Có đầy đủ bệnh án phim X-Quang và CLVT lồng ngực.

\subsubsection{Tiêu chuẩn loại trù̀}

- Không có kết quả giải phẫu bệnh sau phẫu thuật.

- Bệnh nhân được chẩn đoán kén phế quản nhưng không được phẫu thuật.

- Phim chụp XQ và CLVT không đủ để phân tích tổn thương.

\subsection{Phương pháp nghiên cứu}

2.2.1. Thiết kế nghiên cứu: Nghiên cứu mô tả hồi cứu. Xử lý số liệu bằng phần

mềm Stata 10.0. Các thuật toán được sử dụng là tính tỷ lệ \%, tính trung bình, độ lệch $(\mathrm{X} \pm \mathrm{SD})$, các thuật toán kiểm định.

\footnotetext{
* Bệnh viện Phổi trung uơng

** Bệnh viện Việt Đúcc

Ngưòi chịu trách nhiệm khoa học: PGS.TS. Đoàn Quốc Hung

Ngày nhận bài: 18/06/2016 - Ngày Cho Phép Đăng: 18/08/2016

Phản Biện Khoa học: PGS.TS. Đặng Ngọc Hùng
}

GS.TS. Bùi Đúcc Phú 


\section{KẾT QUẢ}

3.1. Phân bố tuổi, giới

Tuổi trung bình $41,8 \pm 11,97$, thấp nhất 15 tuổi, cao nhất 65 tuổi.

Tỷ lệ giới tính nam 19 (43,18\%), nữ $25(56,82 \%)$

3.2.Tiền sử bệnh hô hấp và lý do đi viện. Bảng 3. 1

Tiền sử chẩn đoán điều trị bệnh hô hấp

\begin{tabular}{|c|c|c|c|c|c|c|c|c|c|}
\hline & $\begin{array}{c}\text { Không } \\
\text { TS }\end{array}$ & Lao & $\begin{array}{c}\text { Viêm } \\
\text { Phế quản }\end{array}$ & Kén khí & Ap xe phổi & U phổi & $\begin{array}{l}\text { Giãn phế } \\
\text { quản }\end{array}$ & TDMP & OCMP \\
\hline $\mathrm{n}$ & 18 & 10 & 3 & 3 & 4 & 1 & 2 & 2 & 1 \\
\hline$\%$ & 40.91 & 22,73 & 6.82 & 6.82 & 9.09 & 2.27 & 4.55 & 4.55 & 2.27 \\
\hline \multicolumn{10}{|c|}{ Lý do khám bệnh } \\
\hline & & Ho máu & Đau ngực & Ho khan & Khó thở & $\begin{array}{c}\text { Ho } \\
\text { đờm }\end{array}$ & Sốt & $\begin{array}{c}\text { Đau } \\
\text { khớp }\end{array}$ & Tình cờ \\
\hline $\mathrm{n}$ & & 16 & 12 & 7 & 5 & 4 & 4 & 1 & 1 \\
\hline$\%$ & & 32 & 24 & 14 & 10 & 8 & 8 & 2 & 2 \\
\hline
\end{tabular}

\subsection{Triệu chứng lâm sang chủ yếu. Bảng 3.2}

Triệu chứng lâm sàng chủ yếu

\begin{tabular}{|l|l|c|c|c|c|c|c|}
\hline & & Đau ngực & Khó thở & Ho khan & Ho máu & Đờm mủ & Sốt \\
\hline \multirow{2}{*}{ Trong phổi } & $\mathrm{n}$ & 21 & 7 & 7 & 16 & 11 & 11 \\
\cline { 2 - 8 } & $\%$ & 19.44 & 6.48 & 6.48 & 14.81 & 10.19 & 10.19 \\
\hline \multirow{2}{*}{ Trung thất } & $\mathrm{n}$ & 7 & 7 & 3 & 0 & 3 & 1 \\
\cline { 2 - 8 } & $\%$ & 6.48 & 6.48 & 2.78 & 0 & 2.78 & 0.93 \\
\hline \multirow{2}{*}{ Phổi - Trung thất } & $\mathrm{n}$ & 1 & 2 & 2 & 1 & 0 & 0 \\
\cline { 2 - 9 } & $\%$ & 0.93 & 1.85 & 1.85 & 0.93 & 0 & 0 \\
\hline n chung & 29 & 16 & 12 & 17 & 14 & 12 \\
\hline$\%$ chung & 26.85 & 14.81 & 11.11 & 15.74 & 12.96 & 11.11 \\
\hline
\end{tabular}

3.4.Hình ảnh $X$ quang thường quy phôi: hình ảnh kén. Bảng 3.3

\begin{tabular}{|c|c|c|c|c|c|c|c|c|c|c|}
\hline & \multicolumn{6}{|c|}{ Hình ảnh kén } & \multicolumn{3}{|c|}{ Số lượng kén thường quy } \\
\hline & & $\begin{array}{l}\text { Kén } \\
\text { khí }\end{array}$ & $\begin{array}{l}\text { Dịch } \\
\text { khí }\end{array}$ & $\begin{array}{l}\text { Khối } \\
\text { mờ đều }\end{array}$ & $\begin{array}{c}\text { Mờ không } \\
\text { đều }\end{array}$ & $\begin{array}{c}\text { Mờ trong } \\
\text { kén }\end{array}$ & $\begin{array}{c}\text { Không } \\
\text { rõ }\end{array}$ & $\begin{array}{l}\text { Đơn } \\
\text { kén }\end{array}$ & $\begin{array}{l}\text { Đa } \\
\text { kén }\end{array}$ & $\begin{array}{l}\text { Không } \\
\text { rõ }\end{array}$ \\
\hline \multirow[t]{2}{*}{ Trong phổi } & $\mathrm{n}$ & 12 & 6 & 6 & 3 & 3 & 0 & 19 & 9 & 2 \\
\hline & $\%$ & 27.27 & 13.64 & 13.64 & 6.82 & 6.82 & 0 & 43.18 & 20,46 & 4,55 \\
\hline \multirow[t]{2}{*}{ Trung thất } & $\mathrm{n}$ & 1 & 1 & 8 & 0 & 0 & 1 & 10 & 0 & 1 \\
\hline & $\%$ & 2,27 & 2,27 & 18,18 & 0 & 0 & 2,27 & 22.73 & 0 & 2,27 \\
\hline \multirow{2}{*}{$\begin{array}{l}\text { Phổi - } \\
\text { Trung thất }\end{array}$} & $\mathrm{n}$ & 0 & 0 & 2 & 1 & 0 & 0 & 1 & 2 & 0 \\
\hline & $\%$ & 0 & 0 & 4,55 & 2,27 & 0 & 0 & 2,27 & 4,55 & 0 \\
\hline \multirow[t]{2}{*}{ chung } & $\mathrm{n}$ & & & & & & & 30 & 11 & 3 \\
\hline & $\%$ & & & & & & & 68.18 & 25 & 6,82 \\
\hline
\end{tabular}




\subsection{Hình ảnh cắt lớp vi tính: vị trí - hình ảnh kén.}

Bảng 3.4

\begin{tabular}{|l|c|c|c|c|c|c|}
\hline \multicolumn{2}{|c|}{} & \multicolumn{6}{c|}{ Hình ảnh kén } \\
\cline { 2 - 7 } \multicolumn{2}{|c|}{} & Kén khí & Dịch khí & Khối mờ đều & Mờ không đều & Khối mờ trong kén \\
\hline \multirow{2}{*}{ Trong phổi } & $\mathrm{n}$ & 8 & 9 & 4 & 1 & 8 \\
\cline { 2 - 7 } & $\%$ & 18,18 & 20,45 & 9,09 & 2,27 & 18,18 \\
\hline \multirow{2}{*}{ Trung thất } & $\mathrm{n}$ & 1 & 1 & 9 & 0 & 0 \\
\cline { 2 - 7 } & $\%$ & 2,27 & 2,27 & 20,45 & 0 & 0 \\
\hline \multirow{2}{*}{ Phổi-Trung thất } & $\mathrm{n}$ & 0 & 0 & 3 & 0 & 0 \\
\cline { 2 - 7 } & $\%$ & 0 & 0 & 6,82 & 0 & 0 \\
\hline \multirow{2}{*}{ Chung } & $\mathrm{n}$ & 9 & 10 & 16 & 1 & 8 \\
\cline { 2 - 7 } & $\%$ & 20,45 & 22,73 & 36,36 & 2,77 & 18,18 \\
\hline
\end{tabular}

\section{5.Điều trị:}

Bảng 3.5. Kỹ thuật mổ và tình trạng viêm dính và biến chứng so với vị trí kén.

\begin{tabular}{|l|c|c|c|c|c|c|c|c|c|}
\hline & & $\begin{array}{c}\text { Mổ } \\
\text { mở }\end{array}$ & $\begin{array}{c}\text { Nội } \\
\text { soi }\end{array}$ & $\begin{array}{c}\text { VAT } \\
\mathrm{S}\end{array}$ & $\begin{array}{c}\text { Phổi Viêm } \\
\text { dính }\end{array}$ & $\begin{array}{c}\text { Phổi không } \\
\text { viêm dính }\end{array}$ & $\begin{array}{c}\text { Cắt } \\
\text { kén }\end{array}$ & $\begin{array}{c}\text { Cắt } \\
\text { thùy }\end{array}$ & $\begin{array}{c}\text { Cắt kén } \\
\text { và thùy }\end{array}$ \\
\hline \multirow{3}{*}{ Trong phổi } & $\mathrm{n}$ & 30 & 0 & 0 & 26 & 4 & 2 & 28 & 0 \\
\cline { 2 - 12 } & $\%$ & 68,18 & 0 & 0 & 59,09 & 9,09 & 4,55 & 63,64 & 0 \\
\hline \multirow{2}{*}{ Trung thất } & $\mathrm{n}$ & 7 & 1 & 3 & 7 & 4 & 10 & 0 & 1 \\
\cline { 2 - 12 } & $\%$ & 15,91 & 2,27 & 6.82 & $15, .91$ & 9,09 & 22,73 & 0 & 2,27 \\
\hline \multirow{2}{*}{ Phổi-Trung thất } & $\mathrm{n}$ & 2 & 1 & 0 & 2 & 1 & 1 & 0 & 2 \\
\cline { 2 - 11 } & $\%$ & 4,55 & 2,27 & 0 & 4,55 & $2, .27$ & 2,27 & 0 & 4,55 \\
\hline \multirow{2}{*}{ Chung } & $\mathrm{n}$ & 39 & 2 & 3 & 35 & 9 & 13 & 28 & 3 \\
\hline
\end{tabular}

\section{Bảng 3.6. Biến chứng trong và sau phẫu thuật.}

Biến chứng trong mổ: 2 (4,55 \%) trường hợp chảy máu, 42 (95,45 \%) trường hợp không biến chứng.

Biến chứng sau mổ

\begin{tabular}{|c|c|c|c|c|c|c|}
\hline & & Chảy máu & Viêm phổi & $\begin{array}{l}\text { Viêm } \\
\text { màng phỏi }\end{array}$ & $\begin{array}{l}\text { Dịch/ } \\
\text { khí kéo dài }\end{array}$ & $\begin{array}{c}\text { Nhiễm trùng } \\
\text { vết mố }\end{array}$ \\
\hline \multirow{2}{*}{ Trong phoi } & $\mathrm{n}$ & 1 & 2 & 2 & 8 & 1 \\
\hline & $\%$ & & & & & \\
\hline \multirow{2}{*}{ Trung thất } & $\mathrm{n}$ & 0 & 0 & 0 & 2 & 1 \\
\hline & $\%$ & & & & & \\
\hline \multirow{2}{*}{ Phổi trung thất } & $\mathrm{n}$ & & 0 & 0 & 0 & 0 \\
\hline & $\%$ & & & & & \\
\hline
\end{tabular}

-Tình trạng ra viện $100 \%$ trong tình trạng lâm sàng ổn định, 41 trường hợp trên phim xquang phổi nở sát thành ngực, 3 trường hợp có hình ảnh dày dính màng phổi. 
Bảng 3.7. Đối chiếu kết quả mô bệnh với vị trí kén phế quản

\begin{tabular}{|c|c|c|c|c|c|c|c|}
\hline & & \multicolumn{3}{|c|}{ Giải phẫu bệnh } & \multicolumn{3}{|c|}{ Bên ngực tổn thương } \\
\hline & & $\begin{array}{c}\text { Kén đơn } \\
\text { thuần }\end{array}$ & $\begin{array}{c}\text { Kén bội } \\
\text { nhiêm nấm }\end{array}$ & $\begin{array}{l}\text { Kén bội } \\
\text { nhiễm }\end{array}$ & Ngực phai & Ngực trái & $\begin{array}{c}\text { Giữa } \\
\text { Trung thất }\end{array}$ \\
\hline \multirow[t]{2}{*}{ Trong phổi } & $\mathrm{n}$ & 5 & 11 & 14 & 19 & 11 & 0 \\
\hline & $\%$ & 11,36 & 25 & $31, .82$ & 43,18 & 25,00 & 0 \\
\hline \multirow[t]{2}{*}{ Trung thất } & $\mathrm{n}$ & 11 & 0 & 0 & 3 & 7 & 1 \\
\hline & $\%$ & 25 & 0 & 0 & 6,82 & 15,91 & 2,27 \\
\hline \multirow{2}{*}{$\begin{array}{l}\text { Phổi-Trung } \\
\text { thất }\end{array}$} & $\mathrm{n}$ & 1 & 0 & 2 & 2 & 1 & 0 \\
\hline & $\%$ & 2,27 & 0 & 4,55 & 4,55 & 2,27 & 0 \\
\hline \multirow[t]{2}{*}{ Chung } & $\mathrm{n}$ & 17 & 11 & 16 & 24 & 19 & 1 \\
\hline & $\%$ & 38,64 & 25,00 & 36,36 & 54,56 & 43,18 & 2,27 \\
\hline
\end{tabular}

\section{BÀN LUẬN}

\subsection{Tuổi giới}

- Tuổi: trong nghiên cứu của chúng tôi tuổi trung bình 41,86 tuổi, tương tự như tác giả: Vũ Chí Thành [1] tuổi trung bình 40 tuổi, Faten Limaïem[2] trung bình 41 tuổi.

- Về giới tính: một số nghiên cứu cho rằng tỷ lện nam cao hơn nữ, một số nghiên cứu lại chỉ ra rằng nữ cao hơn nam. Vũ Chí Thành [1] nam/ nữ: 1,2/1; McAdams HP nam/nữ 1,3/1. Trong nghiên cứu của chúng tôi tỷ lệ nam/ nữ: 1/1,3 như vậy sự mắc bệnh của nam và nữ là không có sự khác biệt với $\mathrm{p}>0,05$.

4.2. Tiền sử bệnh, lý do khám bệnh và triệu chứng. [Bảng 3.1 và Bảng 3.2]

- Tiền sử bệnh: 59,09 \% trường hợp trong nghiên cứu được chẩn đoán nhầm sang các bệnh trước khi điều trị thực thụ. Có lẽ bệnh lý này không được chú ý đến khi khám sức khỏe ban đầu. Bệnh chẩn đoán nhiều nhất đó là bệnh Lao, kế đến ap xe phổi, viêm phế quản và kén khí. Hiện tại chưa có nghiên cứu nào nói đến tiền sử chẩn đoán và điều trị các bệnh hô hấp trước đó.

- Lý do khám bệnh: Triệu chứng khiến bệnh nhân khó chịu phải đi viện chủ yếu ho máu và đau ngực, ho máu chủ yếu tổn thương trong phổi, kế đến đau ngực, ho khan/ đờm và sốt. Trong khí đó tổn thương ở trung thất chủ yếu đau ngực, ho khan và khó thở. So với một số nghiên cứu trong nước và thế giới tỷ lệ ho máu trong nghiên cứu là $32,65 \%$ cao hơn hẳn so với nghiên cứu của Vũ Chí Thành (2003) [1] ho ra máu $(21,2 \%)$, đau ngực $(42,4 \%)$ trong khi đau ngực trong nghiên cứu chỉ có $24,49 \%$

Triệu chứng lâm sàng chủ yếu là các triệu chứng chung của bệnh cảnh hô hấp: Ho, ho máu, đau ngực, khó thở, sốt. Điều đó nói nên việc chẩn đoán và điều trị nhầm là dễ hiểu. Các triệu chứng tương tự trong kết quả nghiên cứu Vũ Chí Thành (2003) [1] nghiên cứu 33 bệnh nhân kén phế quản nhận xét triệu chứng chủ yếu là đau ngực chiếm, sốt, ho khan, ho ra máu, khó thở. Theo Faten Limaïem [2] nghiên cứu kén phế quản trung thất $94 \%$ trường hợp có triệu chứng thì có đến $48,5 \%$ là đau ngực.

- Chỉ có một trường hợp tình cờ phát hiện, không có triệu chứng khi khám sức khỏe định kỳ, so với một số tác giả khác là rất thấp: Sarper và cộng sự $18 \%[3]$. Điều đó càng nói lên việc phát hiện và điều trị muôn khi đã có biến chứng.

\subsection{Chẩn đoán hình ảnh. [Bảng 3.3, Bảng 3.4]}

- Bên tổn thương: nhìn các con số có vẻ ngực phải chiếm ưu thế. Sử dụng thuật toán so sánh tỷ lệ thì tổn thương bên ngực phải và trái là khồng có sự khác biệt có $\mathrm{y}$ nghĩa thống kê với $\mathrm{p}=0.445$. Vũ Chí Thành 2003 [1] gặp bện phải cao hơn bênh trái gấp 2 lần. Philippe Cuypers tỷ lệ phải/ trái: 1,7/1. Trong khi đó kén phế quản trong phổi tỷ lệ gặp bên phải cao hơn bên trái, còn kén ở trung thất thì ngược lại tỷ lệ bên trái cao hơn. 
- Vị trí kén phế quản gặp chủ yếu trong phổi hơn là trung thất, sự khác biệt có ý nghĩa thống kê $\mathrm{p}<$ 0,05 , tương tự một số nghiên cứu khác tỷ lệ kén phế quản trung thất ít gặp hơn so ở phổi: Vũ Chí Thành 2003 [1] 100\% kén phế quản phổi, có lẽ các kén phế quản trung thất chưa được quan tâm tới.

- Hình ảnh kén trên phim x quang thường quy: Chủ yếu là dạng khối mờ đồng nhất, kế đến là dạng kén khí, kén mức dịch khí, khối mờ trong kén... điều đó việc chẩn đoán ban đầu dễ nhầm sang bệnh lý khác khi kết hợp với các triệu chứng lâm sàng như lao phổi, u phổi, u trung thất, ap xe phổi.. làm cho việc điều trị thực bị bị chậm trễ. Sunit R. Patel [4] nghiên cứu 18 trường hợp kén phế quản thấy 17 trường hợp có bất thường trên phim chụp $\mathrm{x}$ quang ngực thường quy nhưng không được chẩn đoán. Theo Faten Limaïem [2] trong 27 trường hợp trên phim chụp xquang thường quy thấy 18 trường hợp mờ đồng nhất, 7 trường hợp mức dịch khí, 2 trường hợp xẹp phổi.

- Hình ảnh trên phim CLVT lồng ngực: cho hình ảnh kén phế quản rõ ràng hơn so với phim X-Quang thường quy, đặc biệt các kén nằm ở đường giữa mà trên xquang thường không nhìn thấy được. Các khối mờ đồng nhất được đo tỷ trọng giúp cho việc chẩn đoán phân biệt giữa khối u đặc và nang dịch, thậm chí dạng tổn thương kén khí, dịch khí, khối mờ trong kén cũng rõ ràng hơn. Nhưng việc chẩn đoán xác định các dạng tổn thương kén khí, dịch khí, khối mờ trong kén vẫn dễ nhầm với các bệnh cảnh khác như lao, apxe, u nấm trong hang lao... khi mà tổ chức phổi xung quanh bị viêm nhiễm lâu ngày làm thay đổi hình dáng ban đầu của kén phế quản. McAdams năm 2000 [5] nghiên cứu hình ảnh kén phế quản trung thất trên phim CLVT lồng ngực 58 trường hợp kén phế quản trung thất thấy 25 trường hợp nang dich, 25 trường hợp mô mềm, 2 trường hợp kén khí, 2 trường hợp kén dịch - khí, 2 trường hợp can xi hóa. ..không có mô tả hình ảnh khối mờ trong kén, có lẽ do điều kiện môi trường mà biến chứng nhiêm nấm gặp nhiều ở nước ta.

\section{4. Điều trị. [Bảng 3.5, bảng 3.6]}

- Tại bệnh viện chúng tôi trong 5 năm 2011-2015 điều trị phẫu thuật chủ yếu là mổ mở, mặc dù phẫu thuật nội soi được thực hiện từ lâu xong áp dụng cho điều trị cho phẫu thuật kén phế quản còn hạn chế chỉ có 2 trường hợp được phẫu thuật bằng nội soi, 3 trường hợp mổ mở có nội soi hỗ trợ, còn lại là mổ mở 39 trường hợp.

- Khảo sát trong quá trình phẫu thuật tính trạng viêm dính của phổi kể cả kén trung thất có tỷ lệ cao $79,55 \%$ trường hợp, trong khi đó không viêm dính có $20,45 \%$ trường hợp có lẽ là do không được phát hiện và điều trị sớm khi chưa có biến chứng. Hiện tại chưa có một nghiên cứu nào mô tả ảnh hưởng của biến chứng viêm nhiêm của kén phế quản này.

- Các kén phế quản nằm trong phổi phẫu thuật chủ yếu cắt thùy phổi chứa kén $28 / 30$, có số ít $2 / 30$ trường hợp cắt kén bảo tồn phổi. Kén phế quản trung thất $100 \%$ cắt kén nhưng có 1 trường hợp phải cắt thùy phổi phối hợp di tình trạng viêm của phổi kèm theo. 3 trường hợp có kén cả phổi và trung thất thì có 1 trường hợp cắt nguyên kén, 2 trường hợp cắt kén ở trung thất và cắt thùy chứa kén. Cách thức phẫu thuật là phù hợp với tình trạng tổn thương và tình trạng viêm dính kèm theo của phổi. Theo Vũ Chí Thành 2003[1] 100\% cắt thùy phổi do các kén nằm trong thùy.

- Theo nghiên cứu của Faten Limaïem 32 trường hợp mổ mở 1 trường hợp mổ nội soi lồng ngực. 31 trường hợp cắt kén 1 trường hợp cắt kén từng phần. Theo Philippe Cuypers [6], nghiên cứu 20 trường hợp thì 19 trường hợp mổ mở cắt kén, 1 trường hợp kén phế quản trung thất được mổ nội soi. Theo Sunit R. Patel [4] 22 trường hợp kén phế quản đều mổ mở, 6 trường hợp trong thùy thì 3 trường hợp cắt thùy không điển hình, 3 trường hợp cắt thùy, còn lại kén phế quản trung thất đều cắt kén. Một số tác giả nghiên cứu phẫu thuật nội soi điều trị kén phế quản như: De Giacomo,[7] nghiên cứu 30 trường hợp mổ có nội soi hỗ trợ thì có 28 trường hợp thành công cho thấy được một số ưu điểm của mổ nội soi, chỉ có 2 trường hợp phải chuyển mổ mở. Theo Régent St-Georges [8] 66 trường hợp kén phế quản trung thất được cắt kén trong khi 20 trường hợp kén phế quản trong phổi thì 13 trường hợp cắt thùy, 6 trường hợp cắt tối thiểu, 1 trường hợp phải cắt phổi. 
- Thời gian phẫu thuật thường kéo dài do tình trạng viêm dính của phổi với thành ngực, trung thất, cơ hoành được mô tả khi phẫu thuật, như vậy việc phát hiện và điều trị phẫu thuật sớm sẽ giúp cho phẫu thuật thuận tiện và an toàn hơn cho người bệnh.

- Thời gian nằm viện trung bình cao hơn hẳn so với báo cáo của tác giả Philippe Cuypers [6] thời gian nằm viện trung bình 14,6 ngày, Vũ Chí Thành [1] 13,2 ngày sự khác biệt này không có ý nghĩa thống kê $\mathrm{p}>0,05$.

- Biến chứng trong mổ tỷ lệ thấp và kiểm soát được chủ yếu là chảy máu do viêm dính nhiều mạch tân tạo giữa phổi và thành ngực, một trường hợp phổi viêm dính chắc vào động mạch dưới đòn được xử lý kịp thời tránh được hậu quả đáng tiếc.

- Biến chứng sớm sau mổ (chảy máu, viêm phổi sau mổ), không gặp tử vong sau mổ. Các biến chứng muộn khác thường gặp sau rút dẫn lưu màng phổi, không liên quan tới số lượng dẫn lưu sau mổ, chủ yếu ổ dịch khí khu trú 9 trường hợp. So với các tác giả khác các biến chứng trong nghiên cứu của chúng tôi nhiều hơn hẳn do tình trạng viêm dính, tổn thương phổi phối hợp: Theo Sunit R. Patel [4] chỉ 1 trường hợp rò khí sau mổ. Maria Di Lorenzo [9] nghiên cứu 26 trường hợp ở nhi khoa sau phẫu thuật chỉ có 1 trường hợp viêm phổi, một trường hợp liệt hoành nhẹ ít ngày sau mổ. Theo Vũ Chí Thành [1] biến chứng sau mổ nhẹ và ít: sớm 1 trường hợp chảy máu sau mổ, 1 trường hợp viêm phổi, biến chứng muộn có 3 trường hợp nhiễm trùng vết mổ.

- Khi ra viện $100 \%$ người bệnh trong có lâm sang ổn định, $\mathrm{x}$ quang ngực phổi nở tốt, một số ít trường hợp có viêm dày màng phổi nhẹ. $100 \%$ các trường hợp sau 1-2 tháng khám lại không có biểu hiện biến chứng sau phẫu thuật.

\subsection{Kết quả giải phẫu bệnh. [Bảng 3.7]}

- Giải phẫu bệnh các kén phế quản trung thất đều không có tình trạng bội nhiễm và nấm phát triển. Trong khi đó kén phế quản bội nhiễm và u nấm đều gặp kén ở phổi. Trong 3 trường hợp kén cả ở phổi và trung thất thì có đến 2 trường hợp kén bị bội nhiễm. Điều đó càng nói lên sự cần thiết chẩn đoán sớm và can thiệp kịp thời khi chưa có biến chứng nhất là với thể trong phổi. So với nghiên cứu của Vũ Chí Thành [1] chỉ có $1 / 33$ trường hợp nhiễm nấm Aspergillus. Kén phế quản đơn thuần và bội nhiễm thì tương tự như kết quả của chúng tôi.

\section{KẾT LUẬN}

Kén phế quản là bệnh lý bẩm sinh, chẩn đoán dựa XQ và CLVT lồng ngực. Điều trị triệt để bằng phẫu thuật an toàn, biến chứng ít, nhẹ và tử vong thấp, nhưng cần chẩn đoán và mổ sớm để giảm bớt khó khăn trong mổ.

\section{TÀI LIỆU THAM KHẢO}

1. Vũ Chí Thành (2003), Nghiên cưu đặc điểm lâm sàng Xquang của bệnh nhân kén phế quản, Đại học y Hà nội, Hà Nội.

2. Limaïem, Faten, Ayadi-Kaddour, Aïda, Djilani, Habiba, et al. (2008), "Pulmonary and mediastinal bronchogenic cysts: a clinicopathologic study of 33 cases", Lung. 186(1), pp. 55-61.

3. Sarper, Alpay, Ayten, Arife, Golbasi, Ilhan, et al. (2003), "Bronchogenic cyst", Texas Heart Institute Journal. 30(2), pp. 105-108.

4. Patel, Sunit R, Meeker, David P, Biscotti, Charles $\mathrm{V}$, et al. (1994), "Presentation and management of bronchogenic cysts in the adult", CHEST Journal. 106(1), pp. 79-85.

5. McAdams, H. P., Kirejczyk, W. M., Rosado-deChristenson, M. L., et al. (2000), "Bronchogenic cyst: imaging features with clinical and histopathologic correlation", Radiology. 217(2), pp. 441-6.

6. Cuypers, Philippe, De Leyn, Paul, Cappelle, Lieve, et al. (1996), "Bronchogenic cysts: a review of 20 cases", European journal of cardiothoracic surgery. 10(6), pp. 393-396.

7. De Giacomo, Tiziano, Diso, Daniele, Anile, Marco, et al. (2009), "Thoracoscopic resection of mediastinal bronchogenic cysts in adults", European Journal of Cardio-Thoracic Surgery. 36(2), pp. 357-359.

8. St-Georges, Régent, Deslauriers, Jean, Duranceau, André, et al. (1991), "Clinical spectrum of bronchogenic cysts of the mediastinum and lung in the adult", The Annals of Thoracic Surgery. 52(1), pp. 6-13.

9. Di Lorenzo, Maria, Collin, Pierre-Paul, Vaillancourt, Rosaire, et al. (1989), "Bronchogenic cysts", Journal of pediatric surgery. 24(10), pp. 988-991. 